\title{
Perisylvian Polymicrogyria: Unusual Presentation of Malformation of Cortical Development in an Adult
}

\section{Deepak Menon ${ }^{*}$, Ramsekhar Menon and Bejoy Thomas}

Department of Neurology, SCTIMST, Trivandrum, Kerala, India

"Corresponding author: Deepak Menon, Department of Neurology, SCTIMST, Trivandrum, Kerala, India, Tel: +91 9846311864 ; E-mail: deepakmenon@sctimst.ac.in Received date: July 06, 2015; Accepted date: July 08, 2015; Published date: July 13, 2015

Copyright: $\odot 2015$ Menon D, et al. This is an open-access article distributed under the terms of the Creative Commons Attribution License, which permits unrestricted use, distribution, and reproduction in any medium, provided the original author and source are credited.

\section{Description}

A 42 year old man with no antecedent illness presented with refractory focal seizures having a sensory aura suggestive of left parietal ictal onset since 14 years of age along with poor scholastic performance and non-progressive slurring of speech. He had an IQ of 80 and his examination was notable for spastic dysarthria and subtle bipyramidal signs. His MRI showed bilateral perisylvian polymicrogyria (BPP) and EEG showed bilateral centroparietal IEDs $[1,2]$. BPP are cortical malformations secondary to abnormal postmigrational development, clinically characterized by perisylvian syndrome, mental retardation and seizures. The posterior extension of the polymicrogyria may explain the parietal onset of seizures.
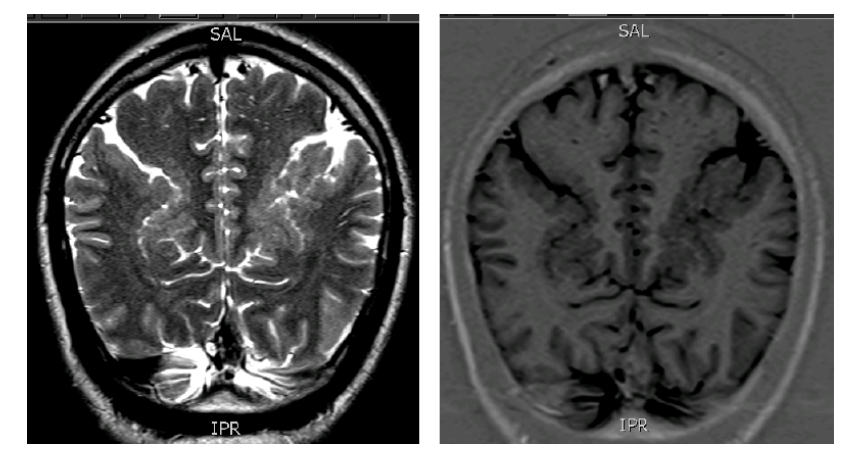

Figure
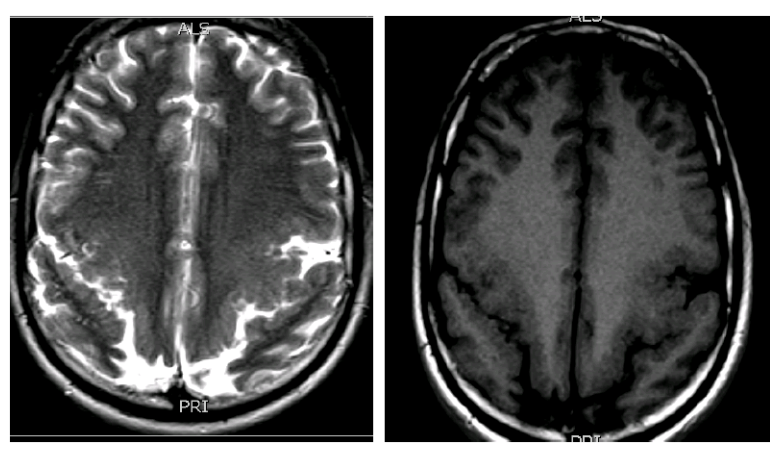

Figure

\section{References}

1. Leventer RJ, Lese CM, Roseberry J (2001) Clinical and morphologic characteristics of polymicrogyria: a magnetic resonance imaging study of 220 patients. Epilepsia 42: 103-104.

2. Barkovich AJ, Hevner R, Guerrini R (1999) Syndromes of bilateral symmetrical polymicrogyria. AJNR Am J Neuroradiol 20: 1814-1821. 